\title{
Effect of Antiepileptic drugs on Psychomotor Functions and Memory in Epilepsy Patients
}

\author{
Mradul Gupta ${ }^{1}$, Prakruti Patel ${ }^{2 *}$, Anuradha Gandhi ${ }^{2}$, Mira Desai ${ }^{2}$ \\ 'Principal Investigator, Cliantha Research Limited, A-2A, Sector 63, Noida-201301, Uttar Pradesh, INDIA. \\ 2Department of Pharmacology, B. J. Medical College, Civil Hospital Ahmedabad, Gujarat, INDIA.
}

\begin{abstract}
Objective: The present study was designed to compare the effect of various antiepileptic drugs on psychomotor and memory function in epileptic patient and to compare them with normal human volunteer. Material \& Methods: It was cross-sectional case control study with a total of 30 cases and 30 controls. All 30 patients were diagnosed cases of Generalised Tonic Clonic Seizure (GTCS) and were on antiepileptic drugs for more than one year. Comparison of patients for all psychomotor tests with the normal subjects matching in age, gender and education was done using unpaired $t$ test. Results: In all the test patients performed poor compared to control group and the difference was significant $(p<0.05)$ for Digit letter substitution test, Choice reaction time (audio and video) where as it was very significant $(p<0.01)$ for Critical flicker fusion test and PGI Memory Scale. In Six-letter cancellation test and Hand steadiness test also patients performed poor compared to subjects but difference was not significant. A further comparison of all the tests was done between patients on monotherapy and polytherapy. PGI Memory scale showed significantly $(p<0.05)$ inferior memory of patients on polytherapy as compared to monotherapy. In all other psychomotor tests also patients on monotherapy had better score compared to polytherapy but differences were not significant. Conclusion: Thus we conclude there is definitely a deterioration of psychomotor and memory with use of antiepileptic drugs.
\end{abstract}

Key words: Epilepsy, Antiepileptic drugs, Psychomotor, Memory, Cognition. Key message: Literature suggests a possible link between antiepileptic drugs and negative consequences on memory and psychomotor function. The patients on antiepileptic drugs performed poor as compared to matching subjects for Digit letter substitution test, Choice reaction time (audio and video), Critical flicker fusion test and PGI Memory Scale. In Six-letter cancellation test and Hand steadiness test also patients performed poor compared to subjects but difference was not significant. Patients on polytherapy showed inferior memory in patients on polytherapy as compared to monotherapy by PGI Memory scale.In all other psychomotor tests also patients on monotherapy had better score compared to polytherapy but differences were not significant.

Correspondence :

Dr. Prakruti P. Patel, Associate Professor, Department of pharmacology, B. J. Medical College, Civil Hospital Ahmedabad, Gujarat, INDIA.

Phone: 9879542949

Email: prakrutiparth@yahoo.co.in

DOI: 10.5530/jyp.2017.9.71

\section{INTRODUCTION}

Epilepsy is a chronic disorder characterized by recurrent seizures, which may vary from a brief lapse of attention or muscle jerks, to severe and prolonged convulsions. ${ }^{1}$ Antiepileptic drugs (AEDs) either as monotherapy or as polytherapy are efficacious in treatment of epilepsy. Studies have demonstrated that antiepileptic drugs affect cognition which may range from subtle to the more prominent features in epileptic patients. ${ }^{2}$ Phenytoin, sodium valproate, phenobarbitone and carbamazepine are the most commonly used antiepileptic drugs. Phenytoin is implicated in dose-related decline in concentration, memory, visuomotor functions and mental speed, as well as generating anxiety, aggression, fatigue, and depression. Sodium valproate can impair concentration, complex decision making, as well as visuomotor function. Studies suggest that the disease as well the treatment reduce psychomotor function. ${ }^{3}$ In addition, a selection of case reports describe reversible parkinsonism and cognitive impairment with chronic use of valproic acid ('valproate encephalopathy'). More recent data denotes that phenobarbital have the greatest behavioral toxic potential with dose related impairment in attention and reaction time, performance IQ and short-term memory, as well as inducing a hyperkinetic syndrome in children. Studies in past have demonstrated decrements in performance of a series of simple psychomotor tests in epileptic patients receiving a supplemental carbamazepine dose. Patients with epilepsy who require high carbamazepine concentrations for optimal control of seizures may be at risk of concurrent impairment of psychomotor function. ${ }^{4}$

The temporal lobe of the brain is important in consolidating memory and language abilities. Patients with chronic temporal lobe epilepsy often have problems with their language and memory abilities because the epilepsy disrupts these functions. ${ }^{5}$ Cognitive function of the brain is the ability to acquire process, integrate, store, and retrieve information. Psychomotor function includes sensorimotor processes such as reaction time and sensorimotor accuracy. Disturbance in these processes leads to patient maladjustment and may impair psychomotor performance, which plays important role in driving and operating complex machinery. Several factors like seizures frequency, etiology and seizure duration have potiential effect on cognative function in patients of epilepsy. ${ }^{6}$

Although the literature suggests a possible link between AEDs and negative consequences on memory and psychomotor function, epilepsy itself may also affect memory and psychomotor functions. Memory and psychomotor functions may also vary with age, gender and education level which work as confounding factors, and hence needed to be matched while selecting controls for the study. So this first case-control study was done to study effect of such antiepileptic drug on psychomotor functions and memory done at a tertiary care hospital.

This is an open access article distributed under the terms of the Creative Commons Attribution-NonCommercial-ShareAlike 4.0 License, which allows others to remix, tweak, and build upon the work non-commercially, as long as the author is credited and the new creations are licensed under the identical terms. 


\section{MATERIALS \& METHODS}

This cross-sectional case control analysis was conducted at Neuromedicine O.P.D and Department of Pharmacology, Civil Hospital Ahmedabad for duration of 10 month. Prior permission to conduct the study was obtained from Head of Unit, Department of Neuromedicine and approval was also obtained from the Institutional Ethics Committee (IEC) [IEC/ Certi/154/14]. An informed written consent was obtained from all patients and volunteers before enrollment in the study.

\section{Case-control study design}

CASES - The investigator visited the OPD on Tuesday and Friday every week from 9:00 am to 1.00 pm. Patients aged 18-65 years of either gender, willing to participate and who gave consent with minimum education of $5^{\text {th }}$ standard in Gujarati or Hindi or English and patient receiving single or multiple antiepileptic drugs for a minimum period of 1 year were included.

Patients of drug resistant epilepsy[Drug resistant epilepsy may be defined as failure of adequate trials of two tolerated and appropriately chosen and used AED schedules (whether as monotherapies or in combination) to achieve sustained seizure freedom], patients suffering from any disease known to affect memory and psychomotor functions (e.g. Depression, Alzheimer's disease, schizophrenia, stroke, mental retardation, Parkinsonism), ${ }^{7,8}$ patients on any drug (s) known to affect memory and psychomotor functions. (Eg. $\mathrm{H}_{1}$ blocker, $\beta$-blocker, anti-depressant, statins, anti-psychotics, hypnotics and sedatives), history of alcohol or any substance abuse and any other chronic disease and pregnant and lactating women were excluded from the study.

CONTROLS - A representative sample of 30 cases were matched with 30 controls and enrolled for the study. The controls for the study were selected after matching age, sex and education level with cases. All controls were selected according to same inclusion and exclusion criteria used for cases except that they were healthy human volunteers without epilepsy.

The data like demographic details, clinical examinations, any concomitant diseases and drug therapy, details of the drug treatment, were recorded in a pre designed Case Record Form (CRF). The patients as well as volunteers were then subjected to following tests to evaluate their psychomotor performance and memory:

Test of perception - Six-letter cancellation test (SLCT): ${ }^{9}$ Patients/ Volunteers were required to cancel as many target digits as possible in a sheet consisting of randomized digits in $90 \mathrm{sec}$. The letter cancellation was carried out in a horizontal, vertical, or randomized manner by selecting any particular key letter. Net score was then calculated as total cancellations attempted minus wrong cancellations.

Test for recognition and recoding - Digit letter substitution test (DLST): ${ }^{10}$ Patients/Volunteers were required to insert the corresponding alphabet in the space above each digit in a sheet consisting of randomized digits in $1 \mathrm{~min}$. The letter substitution was undertaken in horizontal, vertical or randomised manner by selecting a particular digit. Net score was calculated as total substitution attempted minus wrong substitutions.

Test for central integration - Critical flicker fusion test (CFFT): ${ }^{11}$ It is a reliable psychometric test as there is no learning curve effect. ${ }^{12}$ The critical fusion frequency was determined by increasing the frequency from $5 \mathrm{~Hz}$ till a steady light source was seen and the critical flicker frequency by decreasing the frequency from $50 \mathrm{~Hz}$ till flickering was seen. The final reading was an average of all the readings.

\section{Motor component -}

- Test for steadiness: ${ }^{13}$ This is tested by steadiness tester, which consists of holes of different sizes and subjects has to insert stylus into the hole without touching its sides. The error was counted when the stylus touches the walls of hole. Three readings were taken and final reading was an average of all the readings.

- Choice reaction time: ${ }^{14}$ This test is performed on choice reaction time apparatus. There are 2 bulbs of different colours in the apparatus. The bulb is lighted by the investigator by pressing the switch on his side. The volunteer sitting on the opposite side is asked to extinguish the light by pressing the switch on his side. The reaction time required to switch off the light is noted. Three readings are taken and the average of the three is taken as the final reading. For audio component, initially, the volunteer will be conditioned to the two sounds and their corresponding switches. The investigator will press the switch on his side and the time required to recognise the sound and switch off the sound is noted. For each reaction total reaction time are obtained. Three readings are taken and the average of the three is taken as the final reading

Memory testing - PGI Memory Scale (PGIMS): ${ }^{15}$ It has ten different subtests to assess various parameters of memory (e.g. remote memory, recent memory, delayed recall). It is a simple pen and paper test, which can be easily performed in clinical ward or OPD. It takes 20-30 minutes to complete the tests. Overall score range between 0 to 100 .

Statistical analyses: The data was recorded in Microsoft Excel Worksheet version 2007. The statistical evaluation was done using Graph Pad Demo version software. Unpaired t test and One-way ANOVA test was used to compare between two groups and more than two groups respectively. $\mathrm{p}<0.05$ was considered to be statistically significant.

\section{RESULTS}

\section{Patient characteristics}

This cross sectional study at a tertiary care teaching hospital was done with the aim to see the effect of antiepileptic drugs on memory and psychomotor functions as compared to healthy controls. The study included a total of 30 cases and 30 controls. All 30 patients were diagnosed cases of Generalised Tonic Clonic Seizure (GTCS) and were on antiepileptic drugs for more than one year. Out of 30 patients $18(60 \%)$ were males and $12(40 \%)$ females. The average age and weight of patients were $30.2 \pm 9.83$ years and $50.43 \pm 6.47 \mathrm{~kg}$ respectively. Out of 30 patients $20(66 \%)$ had education below or up to secondary level, $02(6.6 \%)$ till higher secondary and remaining $08(26.6 \%)$ were graduates. Upon matching, cases and controls matched in 1:1 ratio based on age, gender and education. The average year of treatment with ADEs was 3.2 \pm 2.46 years and all patients were on stable therapy having no history of seizure in last 6 months. (Table 1)

To test whether chronicity of disease itself had any effect on psychomotor and memory cases were compared by dividing the patients according to the duration of epilepsy. They were grouped as: 1-2 year $(n=12), 2-3$ year $(n=07)$ and $>3(n=11)$ year of disease. Values of all the tests performed were expressed as mean \pm S.E.M. Comparison between various duration group was done using One-way ANOVA test and $P$ value $<0.05$ was considered as significant. (Table 2)

Table 1: Demographic and Clinical characteristics

\begin{tabular}{lcc}
\multicolumn{1}{c}{ Variable } & Case $(\mathrm{n}=\mathbf{3 0})$ & Control $(\mathrm{n}=30)$ \\
\hline Male: Female & $18: 12$ & $18: 12$ \\
Age (years) $($ mean \pm SD) & $30.2 \pm 9.83$ & $29.7 \pm 9.45$ \\
Weight $($ Kg) (mean \pm SD) & $50.43 \pm 6.47$ & $51.06 \pm 6.38$ \\
Education & & \\
1) $\geq$ Secondary & 20 & 20 \\
2) Higher secondary & 02 & 02 \\
3) Graduate & 08 & 08 \\
\hline
\end{tabular}




\begin{tabular}{cccc} 
Table 2: Comparison of Psychomotor and Memory at different durations of epilepsy \\
\hline Test & $\begin{array}{c}1-2 \text { years } \\
(\mathbf{n}=12) \\
\text { mean } \pm \text { S.E.M }\end{array}$ & $\begin{array}{c}2-3 \text { years } \\
(\mathbf{n}=07) \\
\text { mean } \pm \text { S.E.M }\end{array}$ & $\begin{array}{c}>3 \text { years } \\
(\mathbf{n}=11) \\
\text { mean } \pm \text { S.E.M }\end{array}$ \\
\hline Six-letter cancellation test (SLCT) & $26.58 \pm 5.53$ & $28.87 \pm 5.30$ & $28.36 \pm 4.36$ \\
Digit letter substitution test (DLST) & $26.54 \pm 4.72$ & $25.12 \pm 5.10$ & $26.11 \pm 4.87$ \\
Critical flicker fusion test (CFFT) & $42.08 \pm 1.44$ & $43.21 \pm 1.22$ & $42.72 \pm 1.75$ \\
Hand steadiness test & $48.17 \pm 11.49$ & $50.14 \pm 11.19$ & $51.01 \pm 10.44$ \\
Choice reaction time - Audio & $1.54 \pm 0.27$ & $1.44 \pm 0.25$ & $1.47 \pm 0.31$ \\
Choice reaction time - Visual & $1.47 \pm 0.17$ & $1.59 \pm 0.21$ & $1.60 \pm 0.19$ \\
PGI Memory Scale (PGIMS) & $60.00 \pm 2.76$ & $62.42 \pm 2.67$ & $63.18 \pm 3.76$ \\
\hline
\end{tabular}

Note: Test used - One-way ANOVA

No significant differe nce $(\mathrm{p}>0.05)$ between disease duration groups

Table 3: Comparison of Psychomotor and Memory between Monotherapy and Polytherapy

\begin{tabular}{cccc}
\hline Test & $\begin{array}{c}\text { Monotherapy }(\mathbf{n}=\mathbf{1 4}) \\
\text { mean } \pm \text { S.E.M }\end{array}$ & $\begin{array}{c}\text { Polytherapy }(\mathbf{n}=16) \\
\text { mean } \pm \text { S.E.M }\end{array}$ & P value \\
\hline Six-letter cancellation test (SLCT) & $28.28 \pm 1.16$ & $27.00 \pm 1.48$ & 0.50 \\
Digit letter substitution test (DLST) & $26.57 \pm 1.13$ & $25.56 \pm 1.42$ & 0.59 \\
Critical flicker fusion test (CFFT) & $42.85 \pm 0.44$ & $42.34 \pm 0.35$ & 0.37 \\
Hand steadiness test & $48.42 \pm 2.61$ & $50.50 \pm 2.55$ & 0.57 \\
Choice reaction time - Audio & $1.47 \pm 0.07$ & $1.50 \pm 0.06$ & 0.73 \\
Choice reaction time - Visual & $1.52 \pm 0.04$ & $1.56 \pm 0.03$ & 0.52 \\
PGI Memory Scale (PGIMS) & $63.07 \pm 0.92$ & $60.56 \pm 0.74$ & $0.04^{*}$ \\
\hline
\end{tabular}

Note: Test used - Unpaired t test

*Significant difference $(\mathrm{p}<0.05)$ between monotherapy and polytherapy

Table 4: Dose range and average dose

\begin{tabular}{ccc}
\hline Drug & Dose Range Prescribed $(\mathrm{mg})$ & Average Dose (Mean \pm SEM) \\
(Number of patients) & & \\
\hline Sodium valproate (17) & $600-1200$ & $288.88 \pm 7.62$ \\
Phenytoin (18) & $200-400$ & $720 \pm 135.65$ \\
Carbamazepine (5) & $400-1200$ & $90 \pm 7.74$ \\
Phenobarbital (6) & $60-120$ &
\end{tabular}

Among various groups almost similar results were obtained for all the tests performed and no significant difference was seen when comparison was done using one way ANOVA. Another comparison between patients on monotherapy (14) and polytherapy (16) was done using unpaired $t$ test. Values of all the tests performed were expressed as mean \pm S.E.M. $P$ value $<0.05$ was considered as significant. (Table 3 )

As seen in table 3 PGI Memory scale showed significantly $(p<0.05)$ inferior memory of patients on polytherapy as compared to monotherapy. In all other psychomotor tests also patients on monotherapy had better score compared to polytherapy but differences were not significant.

Monotherapy was prescribed in 14 patients out of which 07 were on valproate, 04 on phenytoin and 03 on carbamazepine. Polytherapy was given in 16 patients of which most common combination was valproate + phenytoin (08 patient) followed by phenytoin + phenobarbital (and carbamazepine + valproate (02 patient). Before evaluating effect of individual drugs on psychomotor and memory, range and average dose of all individual drugs prescribed to patients enrolled in the study was tabulated. All drugs were found to be prescribed in the recommended dose range according to standard pharmacological textbooks. (Table 4)

A further comparison between individual drugs was done. Values of all the tests performed are expressed as mean \pm S.E.M. All drugs produced similar results with no individual drug or particular combination better than other. (Table 5)

The effect of antiepileptic drugs on psychomotor and memory was assessed by various tests performed both on patients as well as on normal subjects. Values of all the tests performed were expressed as mean \pm S.E.M. Comparison with the normal subjects was done using unpaired t test. $P$ value $<0.05$ was considered as significant. (Table 6)

In all the patients the values of the test were performed poor compared to matching controls and the difference was significant $(p<0.05)$ for DLTS, Choice reaction time (audio and video) where as it was very significant $(p<0.01)$ for CFFT and PGIMS. In SLCT and Hand steadiness test also patients performed poor compared to subjects but difference was not significant. 
Table 5: Mean score of individual drugs and combinations

\begin{tabular}{cccccccc}
\hline DRUG & $\begin{array}{c}\text { Six-letter } \\
\text { cancellation } \\
\text { test (SLCT) }\end{array}$ & $\begin{array}{c}\text { Digit letter } \\
\text { substitution } \\
\text { test (DLST) }\end{array}$ & $\begin{array}{c}\text { Critical flicker } \\
\text { fusion test } \\
\text { (CFFT) }\end{array}$ & $\begin{array}{c}\text { Hand } \\
\text { steadiness } \\
\text { test }\end{array}$ & $\begin{array}{c}\text { Choice } \\
\text { reaction } \\
\text { time - Audio }\end{array}$ & $\begin{array}{c}\text { Choice } \\
\text { reaction } \\
\text { time - Visual }\end{array}$ & $\begin{array}{c}\text { PGI Memory } \\
\text { Scale (PGIMS) }\end{array}$ \\
\hline $\begin{array}{c}\text { Sodium valproate (07) } \\
\text { Phenytoin (04) }\end{array}$ & $27.96 \pm 1.25$ & $26.63 \pm 1.17$ & $42.16 \pm 0.49$ & $49.06 \pm 2.53$ & $1.42 \pm 0.08$ & $1.58 \pm 0.05$ & $62.86 \pm 0.98$ \\
$\begin{array}{c}\text { Carbamazepine (03) } \\
\text { Valpraote + Phenytoin }\end{array}$ & $28.57 \pm 1.19$ & $26.51 \pm 1.18$ & $43.14 \pm 0.47$ & $48.12 \pm 2.67$ & $1.51 \pm 0.09$ & $1.46 \pm 0.04$ & $63.27 \pm 0.97$ \\
$\quad$ (08) & $26.84 \pm 1.55$ & $25.60 \pm 1.51$ & $42.12 \pm 0.38$ & $50.65 \pm 2.61$ & $1.40 \pm 0.07$ & $1.51 \pm 0.04$ & $61.24 \pm 0.81$ \\
$\quad \begin{array}{c}\text { Phenytoin + } \\
\text { Phenobarbital (06) }\end{array}$ & $27.12 \pm 1.52$ & $25.52 \pm 1.37$ & $42.49 \pm 0.32$ & $50.36 \pm 2.63$ & $1.60 \pm 0.08$ & $1.59 \pm 0.03$ & $60.22 \pm 0.83$ \\
$\begin{array}{c}\text { Carbamazepine + } \\
\text { Valproate (02) }\end{array}$ & $27.20 \pm 1.41$ & $25.48 \pm 1.44$ & $42.37 \pm 0.34$ & $50.30 \pm 2.52$ & $1.52 \pm 0.07$ & $1.60 \pm 0.04$ & $60.31 \pm 0.71$ \\
\hline
\end{tabular}

Table 6: Comparison of Psychomotor and Memory between Case and Control

\begin{tabular}{cccc}
\hline Test & $\begin{array}{c}\text { Case }(\mathrm{n}=30) \\
\text { mean } \pm \text { S.E.M }\end{array}$ & $\begin{array}{c}\text { Control }(\mathbf{n}=30) \\
\text { mean } \pm \text { S.E.M }\end{array}$ & p-value \\
\hline Six-letter cancellation test (SLCT) & $27.60 \pm 0.95$ & $29.70 \pm 0.78$ & 0.094 \\
Digit letter substitution test (DLST) & $26.03 \pm 0.91$ & $28.93 \pm 0.73$ & $0.016^{*}$ \\
Critical flicker fusion test (CFFT) & $42.50 \pm 0.26$ & $43.66 \pm 0.26$ & $0.0028^{* *}$ \\
Hand steadiness test & $49.53 \pm 1.80$ & $48.10 \pm 1.70$ & 0.56 \\
Choice reaction time - Audio & $1.49 \pm 0.04$ & $1.35 \pm 0.04$ & $0.036^{*}$ \\
Choice reaction time - Visual & $1.54 \pm 0.02$ & $1.40 \pm 0.04$ & $0.012^{*}$ \\
PGI Memory Scale (PGIMS) & $61.73 \pm 0.61$ & $64.20 \pm 0.64$ & $0.0077^{* *}$ \\
\hline
\end{tabular}

Note: Test used - Unpaired t test

*Significant difference $(\mathrm{p}<0.05)$ between case and control

${ }^{*}$ Very significant difference $(\mathrm{p}<0.01)$ between case and control

\section{DISCUSSION}

Epilepsy is a chronic disorder which needs lifelong treatment with Antiepileptic drugs (AEDs) either as monotherapy or as polytherapy. As epilepsy is produced by widespread and uniform process within the cortex of the brain, epilepsy itself may effect memory and psychomotor functions. Although the literature suggests a possible link between AEDs and negative consequences on memory and psychomotor function, a very few studies test a hypothesis of a specific association. So this first case-control study was done to study effect of such antiepileptic drug on psychomotor functions and memory done at a tertiary care teaching hospital.

The average age of patients in our study was $30.2 \pm 9.83$ years This is similar to a study conducted in Malaysia ${ }^{16}$ that reported a mean age of patients of epilepsy to be $31.8 \pm 11$ years. However, observations made in Brazil ${ }^{17}$ and South India, ${ }^{18}$ reported that the mean age of patients suffering from epilepsy to be $43.86 \pm 13.98$ and $34.89 \pm 9.22$ years respectively. In our study $60 \%$ were males while remaining $40 \%$ females which is to studies done in Ethopia ${ }^{19}$ and South India. In our study $66 \%$ of patients had education till secondary level while remaining $33 \%$ had higher education. One of the Indian study also showed similar results where $77 \%$ of patients were either primary or secondary education and the remaining $23 \%$ had higher education.

In our study the duration of disease did not show any significant difference in psychomotor skills as well as memory of patients suffering with epilepsy. The possible reason is, we had enrolled only those patients who were stable with no seizure attack in last six month. It also showed that if epilepsy is well controlled with ADEs chronicity of disease didn't affect memory and psychomotor skills. One more observation made in our study was significant deterioration of memory in patients on polytherapy as compared to monotherapy. In all other psychomotor tests also patients on monotherapy had better score compared to polytherapy but differences were not significant. Similar to our study Gillham et al, $1991^{20}$ also observed that polytherapy group had worse effect on memory and psychomotor function than monotherapy and controls for decision and choice reaction time. A Ethopian study also reported that polytherapy offers no advantage over monotherapy. ${ }^{21}$ Thus increase in the number of AEDs effect memory and psychomotor skills by suppressing neuronal excitability or enhancing inhibitory neurotransmission.

To further confirm the effect of AEDs on memory and psychomotor skills we did a comparison of our patients with healthy volunteers matching in age, gender and education level as these are the confounding factors also effecting memory and psychomotor skills. No significant difference between patients and healthy volunteers was seen in SLCT which tests a person's ability of perception and attention. But a significant deterioration among patients was seen in Digital letter substitution test which also tests perception and attention. Overall it indicates that AEDs deteriorate level of perception and attention. Hand steadiness test which tests for motor component produced similar results in both case and control groups. It indicates that AEDs don't deteriorate motor coordination. But a significant deterioration among patients was seen in critical flicker fusion test, Choice reaction time both of which tests cognition, central integration. It indicates that AEDs also lowers the level of cognition and central integrity. PGIMS which is used specifically to test memory was also deteriorated to a great deal with the use of AEDs in patients compared to controls. Similar results were observed by Craig-Tallis et al, $1994^{22}$ 
where decrement in cognitive function and reaction time was seen with use of AEDs. But contrary to our finding Craig Tallis study showed improvement in memory. Study done by Meador et al, $2003^{23}$ for sodium valproate showed cognitive impairment as compared to placebo. Study done by Sun et al, $2008^{24}$ reports no increase in reaction time with little evidence of attentional impairment. At the same time there are studies which observed no deterioration of cognition with use of AEDs (Spitz et al, 1991) $)^{25}$

Our study indicates that patients of epilepsy which are treated with antiepileptic drugs have poor psychomotor skills as well as memory as compared to general population. Amongst all the antiepileptic drug studies show that Phenobarbital shows maximum dose related behavioral toxic potential. Study by Cavanna AE shows that phenytoin declines memory, concentration, visuomotor functions and mental speed. The active metabolite of carbamazepine i.e. carbamazepine epoxide is at least partially responsible for cognitive and psychomotor effect. Valporic acid also impairs concentration and complex decision making and vasomotor function. ${ }^{26}$ This deterioration can be attributed to disease itself or antiepileptic drugs or both. But since only those patients were enrolled in whom disease was well controlled and chronicity of disease didn't show any change in psychomotor skills and memory, contribution of disease in deterioration of psychomotor and memory seems less likely. It is more likely due to use of antiepileptic drugs and use of polytherapy further deteriorates the condition. Hence, we can conclude that antiepileptic drugs i.e. phenytoin sodium valporate, and carbamazepine, along with other drugs used in combinations effect perception, attention, cognation, central integration as well as memory. The effect was more in patients who were on polytherapy than monotherapy.

However, there were few limitations in our study. We used a less number of patients, newer AEDs were not evaluated as ours is government hospital where newer AEDs are not available and children were not enrolled in whom memory and psychomotor skill are in developmental phase and are more likely to get effected by use of ADEs.

\section{CONCLUSION}

As our study and most other study point out that there is definitely a deterioration of psychomotor and memory with use of AEDs, and hence this component should be considered while prescribing drug therapy. Further if the epilepsy is well controlled an attempt toward tapering of drug therapy to minimum level can improve memory and psychomotor functions. This will help epilepsy patients to perform more skilful jobs andthus improving their quality of life also.

\section{ACKNOWLEDGEMENT}

The authors are thankful to Dr Bipin R. Patel, Professor and Head, Department of Neuromedicine, Civil Hospital, Ahmedabad for his valuable inputs in the study.

\section{CONFLICT OF INTEREST}

There are no conflicts of interest.

\section{REFERENCES}

1. World Health Organization, Epilepsy: Fact sheet 2015. Available from http:// www.who.int/mediacentre/factsheets/fs999/en/. [Last accessed on September 15, 2015].

2. Park SP, Kwon SH. Cognitive Effects of Antiepileptic drugs. Journal of Clinical Neurology (Seoul, Korea). 2008;4(3):99-106. https://doi.org/10.3988/jcn.2008.
4.3.99; PMid:19513311 PMCid:PMC2686875

3. Brodie MJ, McPhail E, Macphee GJ, Larkin JG, Gray JM. Psychomotor impairment and anticonvulsant therapy in adult epileptic patients. European journal of Clinical pharmacology. 1987;1;31(6):655-60

4. Eddy CM, Rickards HE, Cavanna AE. The cognitive impact of antiepileptic drugs Therapeutic Advances in Neurological Disorders. 2011;4(6):385-407. https://doi. org/10.1177/1756285611417920; PMid:22164192 PMCid:PMC3229254.

5. Zhao F, Kang H, You Li, Rastogi P, Venkatesh D, Chandra M. Neuropsychological deficits in temporal lobe epilepsy: A comprehensive review. Annals of Indian Academy of Neurology. 2014;17(4):374-82. https://doi.org/10.4103/0972-2327. 144003; PMid:25506156 PMCid:PMC4251008.

6. Aldenkamp, AlphertsWCJ, Sandstedt P et. Antiepileptic Drug-Realted cognative complaints in Seizure free children with epilepsy before and after drug discontinuation. Epilepsia. 1998;39(10):1070-4 https://doi.org/10.1111/j.1528-1157.1998. tb01292.x; PMid:9776327.

7. Pershad D, Wig NN. Revised manual for PGIMS. National Psychological Corporation, Agra 1977.

8. Hietanen $\mathrm{M}$, Teravaine $\mathrm{H}$. The effect of age of disease onset in neuropsychological performance in Parkinson's disease. J Neurol Neurosurg Psychiatry. 1988;51(2): 244-9. https://doi.org/10.1136/jnnp.51.2.244; PMid:3346689 PMCid:PMC1031537.

9. Morrens M, Hulstijn W, Sabbe B. Psychomotor slowing in schizophrenia. Schizophr Bull. 2007;33(4):1038-53. https://doi.org/10.1093/schbul/sbl051 ; PMid:17093141 PMCid:PMC2632327.

10. Stone BM. Pencil and paper tests - sensitivity to psychotropic drugs. British journal of Clinical Pharmacology.1984;18(S1):15 S-20S. Doi 10.1111/j. 1365-2125.

11. Manual on Clinical Pharmacology. Workshop on clinical pharmacology, Chandigarh: Postgrad Inst Med Ed Res (PGIMER) 2000

12. Turner $\mathrm{P}$. Critical flicker frequency and centrally acting drugs. $\mathrm{Br} \mathrm{J}$ Ophthalmol. 1968;52(3):245-50. https://doi.org/10.1136/bjo.52.3.245; PMid:4384626 PMCid:PMC506563.

13. Parkin C, Kerr JS, Hindmarch I. The effects of practice on choice reaction time and critical flicker fusion threshold. Hum Psychopharmacol. 1997;12(1):65-70 https://doi.org/10.1002/(SICI)1099-1077(199701/02)12:1<65::AIDHUP838>3.0.CO;2-W

14. Seth GS. Techniques in Pharmacology. Mumbai: Med Coll and KEM Hosp; Manual Pharmatech. 1996.

15. Yu1 G, Maskray V, Jackson SD, Swift CG, Tiplady B. Department of Health Care of the Elderly, King's College School of Medicine and Dentistry, London SE22 and 2Astra Clinical Research Unit, Edinburgh Br J clin Pharmac. 1991;32:341-5

16. Norsa'adah B, Zainab J, Knight A. The quality of life of people with epilepsy at a tertiary referral centre in Malaysia. Health and Quality of Life Outcomes. 2013;11(1):143. https://doi.org/10.1186/1477-7525-11-143; PMid:23972031 PMCid:PMC3765436.

17. de Almeida Souza TGM, Correa FL, Marin CR. Epilepsy and quality of life: socio-demographic and clinical aspects, and psychiatric co-morbidity. Arq Neuro-Psiquiat. 2013;71(6):385-91. https://doi.org/10.1590/0004-282X20130044; PMid:23828532.

18. Vanitha Rani N et al, Int J Res Pharm Sci. 2013;4:(2)141-5

19. Tegegne MT, Muluneh NY, Wochamo TT, Awoke AA, Mossie TB, MA Yesigat. Assessment of Quality of Life and Associated Factors among People with Epilepsy Attending at Amanuel Mental Specialized Hospital, Addis Ababa, Ethiopia, Science Journal of Public Health. 2014;5(2):378-83.

20. Gillham RA, Read CL, McKee PJM, Larkin JG, Brodie MJ. Cognitive function in epileptic patients on long-term sodium valproate. J Epilepsy. 1991;4(4):205-10. https://doi.org/10.1016/0896-6974(91)90077-V.

21. Gurshaw M, Agalu A, Chanie T. Anti-epileptic drug utilization and treatment outcome among epileptic patients on follow-up in a resource poor setting Journal of Young Pharmacists. 2014;6(3):47

22. Craig I, Tallis R. Impact of valproate and phenytoin on cognitive function in elderly patients - results of a single-blind randomized comparative study. Epilepsia 1994;35(2):381-90. https://doi.org/10.1111/j.1528-1157.1994.tb02448.x PMid:8156961.

23. Madeor KJ, Loring DW, Hulihan JF, Kamin M, Karim R. Differential cognitive and behavioural effects of topiramate and valproate. Neurology. 2003;60(9):1483-8. https://doi.org/10.1212/01.WNL.0000063308.22506.19.

24. Sun $W$, Wang $Y$, Wang $W$, Wu $X$. Attention changes in epilepsy patients following 3-month topiramate or valproate treatment revealed by event-related potential. Int J Psychophysiol. 2008;68(3):235-41 https://doi.org/10.1016/j.ijpsycho.2008.02.003; PMid:18378030.

25. Spitz MC, Deasy DN. Conversion to sodium valproate in nonretarded adults with primary generalized tonic clonic seizures. J Epilepsy. 1991;4(1):33-8. https://doi.org/10.1016/0896-6974(91)90120-8.

26. Cavanna AE, Ali F, Rickards HE, McCorry D. Behavioural and Cognitive effects of anti-epileptic drugs. Discovery Medicine. 2010;20;9(35):138-44. 